services generally falling below the recommended standards. Although the focus on A\&E provides an opportunity to increase liaison psychiatry services for one hospital department, there is a risk that the needs of other patient groups will be neglected. When services are planned the whole hospital should be considered to ensure that all patients receive comprehensive care.

\section{Declaration of interest}

None.

\section{Acknowledgements}

We thank Brendan McLoughlin and the London Development Centre for Mental Health who supported the study. We also thank all the liaison psychiatry staff who participated in this survey.

\section{References}

DEPARTMENT OF HEALTH (1999)

gov.uk/mayor/health/mentalhealth National Service Framework for Mental availability/mentalhealth_highlights.pdf Health: Modern Standards and Service Models. London: Department of Health.

ROYAL COLLEGE OF PHYSICIANS \& ROYAL COLLEGE OF PSYCHIATRISTS (2003) The Psychological Care of Medical Patients: A Practical Guide

DEPARTMENT OF HEALTH (2001)

Reforming Emergency Care: First Steps of a New Approach. London:

Department of Health.

HOWE, A., HENDRY, J. \& POTOKAR, J. (2003) A survey of liaison psychiatry services in the south-west of England. Psychiatric Bulletin, 27, 90-92.

MAYOR OF LONDON (2003) Availability of Mental Health Services in London. Highlights of a Report to the Mayor of London. London: Greater London Authority. http://www.london.

(Council Report CR108). London: Royal College of Physicians \& Royal College of Psychiatrists.

RUDDY, R. \& HOUSE, A. (2003) A standard liaison psychiatry service structure? A study of the liaison psychiatry services within six strategic health authorities. Psychiatric Bulletin, $27,457-460$.

SWIFT, G. \& GUTHRIE, E. (2003) Liaison psychiatry continues to expand: developing services in the British Isles. Psychiatric Bulletin, 27, 339-341.

Tamsin Kewley Specialist Registrar， *Jim Bolton Consultant Liaison Psychiatrist, Department of Liaison Psychiatry, St Helier Hospital, Wrythe Lane, Carshalton, Surrey SM5 1AA, e-mail: jim.Bolton@swlstg-tr.nhs.uk

\title{
Knowledge of deep vein thrombosis among intravenous drug misusers
}

\author{
AIMS AND METHOD
All patients attending the local \\ All patients attending the local \\ supervised drug consumption clinics \\ were surveyed over a month. \\ They were asked via a \\ questionnaire to list the risks \\ of injecting drugs, particularly \\ the symptoms and consequences \\ of deep vein thrombosis \\ (DVT). Of 69 patients \\ surveyed, 46 agreed to take \\ part.
}

Deep vein thrombosis (DVT) is a complication particularly associated with groin injecting in intravenous drug misuse (Roszler et al, 1989; Baldeweg, 2000; MacKenzie et al, 2000; McColl et al, 2001). There has been an increase in the numbers of drug misusers admitted to general hospitals in Gloucestershire with DVT, from 3 in 1998 to 20 in 2003. We suspect that this increase may be owing to an increased incidence of groin injecting. The large size of the groin vein makes it easy to locate, and it may be the last vein left when all others are impossible to use. It also has less of an impact on cosmetic appearance than other injection sites, and some users report a quicker/ better drug effect. Regular use of the groin site leads to a characteristic 'dimple' in the skin over the vein, making location of the site easier for the drug misuser. No survey or study of this type has been conducted in Gloucestershire before. Studies on the increased risk of DVT in the

\begin{abstract}
symptoms. The best informed were those who had experienced thrombosis themselves recently.

CLINICAL IMPLICATIONS

The results indicate an apparent lack of basic knowledge about the risks of DVT in this sample of drug misusers, and a need for some new initiatives to address health education in this area for all drug misusers.
\end{abstract}

original papers drug misuse population seem to have been mainly published in radiology or medical journals (Roszler et al, 1989; Baldeweg, 2000). Studies have focused on the medical outcomes or treatments available (MacKenzie et $a l, 2000)$. The issue of prevention of DVT has not generally been considered. When the prevention of drug misuse by injection is discussed in the literature it is most likely to concentrate on the spread of HIV (Williams et al, 1997) or other blood-borne viral infections.

\section{Method}

All patients attending the local supervised drug consumption clinics were surveyed over 1 month. All patients were opiate misusers currently on a replacement regime of methadone or buprenorphine requiring daily attendance. The only exclusion criterion was refusal by the patient. The participants were asked via a 
Table 1. Patients' knowledge of deep vein thrombosis (DVT) and its consequences $(n=46)$

original

papers

\begin{tabular}{|c|c|c|}
\hline & $\begin{array}{l}\text { Symptom or } \\
\text { consequence listed }\end{array}$ & $\begin{array}{l}\text { Patients } \\
n(\%)\end{array}$ \\
\hline \multirow{5}{*}{$\begin{array}{l}\text { What are } \\
\text { symptoms of DVT? }\end{array}$} & Pain & $30(65)$ \\
\hline & Redness & $12(26)$ \\
\hline & Swelling & $34(74)$ \\
\hline & Areas feel hot & $3(7)$ \\
\hline & Stiffness & $13(28)$ \\
\hline \multirow{6}{*}{$\begin{array}{l}\text { Other symptoms } \\
\text { volunteered by } \\
\text { patient }\end{array}$} & Numbness & $7(15)$ \\
\hline & Tingling & $13(28)$ \\
\hline & Fever or malaise & $6(13)$ \\
\hline & Bruising or skin changes & $4(9)$ \\
\hline & $\begin{array}{l}\text { Lump or weeping at the } \\
\text { site }\end{array}$ & $1(2)$ \\
\hline & Burning when injecting & $1(2)$ \\
\hline \multirow{5}{*}{$\begin{array}{l}\text { What are } \\
\text { consequences of } \\
\text { DVT? }\end{array}$} & Pulmonary embolus & $13(28)$ \\
\hline & Death & $27(59)$ \\
\hline & Vein damage & $8(17)$ \\
\hline & $\begin{array}{l}\text { Long-term medication } \\
\text { (warfarin) }\end{array}$ & $11(24)$ \\
\hline & $\begin{array}{l}\text { Increased risk of further } \\
\text { DVT }\end{array}$ & $0 \quad(0)$ \\
\hline \multirow{3}{*}{$\begin{array}{l}\text { Other consequences } \\
\text { volunteered by } \\
\text { patient }\end{array}$} & Loss of a limb & $23(50)$ \\
\hline & Heart attack or stroke & $5(11)$ \\
\hline & Septicaemia & $2(4)$ \\
\hline
\end{tabular}

questionnaire to list the risks of injecting, particularly into the groin. They were asked which sites they had used to inject and how they had learned their injecting technique. They were also asked to list the symptoms and consequences of DVT and whether they or anyone they knew had ever had a thrombosis. The questionnaire was administered verbally so participants could respond freely and were not prompted to list symptoms.

\section{Results}

Of 69 patients, 46 agreed to take part: 37 (80\%) male and $9(20 \%)$ female; mean age 31 years 8 months. Twenty-three patients refused to take part, of whom 14 (61\%) were male and the mean age was 29 years 7 months. All patients were opiate misusers but only 9 (20\%) had never injected drugs. Over half had taught themselves to inject (54\%, 21 patients). Among patients who had ever injected, arms (37, 100\%) and hands (35, $95 \%$ ) were the most common injection sites but $43 \%$ of patients (16) had injected into their groins and $57 \%$ into their necks (21 patients). Use of femoral veins was associated with lack of alternative venous access $(14,88 \%)$, easier technique $(3,19 \%)$ and improved drug effect $(2$, $13 \%)$; no one claimed that it was for cosmetic reasons. Ten patients (22\%) had experienced a venous thrombosis themselves and 35 (76\%) knew of someone else who had.

Although 34 (74\%) listed thrombosis as a risk of groin injecting, only $30(65 \%)$ knew what a clot or thrombosis actually was. Thirty-four (74\%) correctly identified that pain and 30 (65\%) that swelling were associated symptoms, but few knew of other symptoms

(Table 1). Twenty-seven patients (59\%) reported that death could occur as a result of thrombosis and 23 (50\%) thought that amputation of a limb was likely. Other consequences were reported by less than $30 \%$.

\section{Discussion}

Femoral veins are frequently used as an injection site by drug misusers in urban Gloucestershire. There appears to be a lack of basic knowledge about the risks and symptoms of DVT among drug misusers, despite increased admissions for treatment of thromboses and the provision of harm reduction leaflets to all drug misusers in our service (Gloucestershire Partnership Trust, 2001).

One of the most interesting findings of this survey was the widely differing level of knowledge between patients interviewed. A small subset of patients had experienced a DVT within the past few months and had been referred to the drug misuse service by the general physicians who had treated them in the local district general hospital. These patients were the best informed about DVT and its symptoms and consequences. It is possible that these patients caused the results of this survey to be skewed, with an over-reporting of the knowledge of DVT. It may also cause an over-reporting of the numbers of drug misusers who have personally experienced a DVT.

The survey did show that over half the patients interviewed had taught themselves to inject drugs, including a groin injecting technique. It is possible that this is one cause of poor injecting technique among drug misusers and would predispose them to the development of venous thrombosis.

The results indicate the need for some new initiatives to address health education in this area for all drug misusers. It is worth considering that this survey only addresses those patients who are actually on substitute medication and attending the supervised clinics. It has therefore missed patients who have not yet reached the stage in their addiction where they wish to access services. The knowledge of DVT of users not in contact with services is likely to be much lower than that reported here, and their risks consequently higher.

\section{Declaration of interest.}

None.

\section{References}

BALDEWEG, S. E. (2000) Injecting drug use is a major risk factor for deep vein thrombosis. BMJ, 321, 1018.

GLOUCESTERSHIRE PARTNERSHIP TRUST (2001) Harm Reduction (Advice About Safer Drug Use). Gloucester: Severn Enterprise.

LINNELL, M. (2003) Going InThe Groin: Injecting in the Femoral Vein. Manchester: Lifeline Publications.
MacKENZIE, A. R., LAING, R. B. S DOUGLAS, J. G., et al (2000) High prevalence of iliofemoral venous thrombosis with severe groin infection among injecting drug users in North East Scotland: successful use of low molecular weight heparin with antibiotics. Postgraduate Medical Journal, 76, 561-565.

MCCOLL, M. D., TAIT, R. O., GREER, I. A., et al (2001) Injecting drug use is a risk 
factor for deep vein thrombosis in women in Glasgow. British Journal of Haematology, 112, 641

ROSZLER, M. H., MCCARROLL, K. A., DONOVAN, K. R., et al (1989) The groin hit: complications of intravenous drug abuse. Radiographics, 9, 487 508

WILLIAMS, P. G., ANSELL, S. M. \& MILNE, F. J. (1997) Illicit intravenous drug use in Johannesburg - medical complications and prevalence of HIV

infection. South African Medical Journal, 87, 889-891.

Karen Williams Consultant Psychiatrist, AddictionTreatment Unit, Gloucester, *Emma Abbey Specialist Registrar, Wotton Lawn Hospital, Horton Road, Gloucester GL1 3WL, e-mail: emma.abbey@glos.nhs.uk

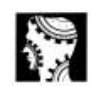

original papers

\section{Driving, dementia and the Driver and Vehicle Licensing Agency: a survey of old age psychiatrists}

\section{AIMS AND METHOD}

We surveyed old age psychiatrists in the north-east of England to determine what they considered relevant indicators of driving ability. The survey asked about their satisfaction with the current Driver and Vehicle Licensing Agency (DVLA) procedure of assessing competence to drive in patients with dementia and how they thought this could be improved.

\section{RESULTS}

Fifty-seven out of 76 psychiatrists (75\%) responded; 26 (45\%) respondents thought the forms issued by the DVLA were unsatisfactory but 32 $(57 \%)$ were satisfied with the eventual decisions made about individual patients. Factors thought to be relevant indicators of driving ability were occupational therapy $(n=46,81 \%)$, neuropsychological assessments ( $n=43,75 \%)$ and carer's report of driving $(n=48,84 \%)$. Factors thought not to be relevant were patient's report of driving ability $(n=13,23 \%)$ and the Mini Mental State Examination ( $n=21,38 \%)$.

\section{CLINICAL IMPLICATIONS}

The current system for determining driving ability in people with cognitive impairment and dementia was felt to be unsatisfactory. A multidisciplinary approach and use of onroad driving assessments may improve decision-making.
Over two million people over the age of 70 hold a current driving licence in the UK and this is estimated to increase to four and a half million by 2013 (Department of Transport, 2001). Since age is an important risk factor for dementia the number of drivers with dementia is expected to increase. A retrospective analysis of referrals to a memory clinic in Somerset revealed that 20\% were still driving (Kolowski \& Rossiter, 2000). A brief analysis of 250 police reports of accidents in 1995 showed that dementia was the most common psychiatric disorder when disability or illness was implicated as a cause (Harris, 2000). Although it is important to consider the risks of driving for people with dementia, it is also important to make appropriate decisions since cessation of driving can have a significant negative impact on the patient and their family (Taylor \& Tripodes, 2001) and driving skills can be retained in the early stages of dementia.

In the UK only the Driver and Vehicle Licensing Agency (DVLA) holds statutory responsibility for decisions on whether a person can hold a driver's licence but most decisions are based on medical reports (British Psychological Society, 2001). There are no specific forms for drivers with cognitive impairment and medical reports for drivers with dementia are usually completed on forms issued for neurological impairment. There are no clinical tests available to predict driving ability in patients with cognitive impairment. On-road assessments have been described as a more reliable method (Lloyd et al, 2001; Dobbs et al, 2002).
There are few studies from the UK on the driving ability of patients with dementia. We surveyed old age psychiatrists in the north-east of England and the Borders to determine what they considered relevant indicators of driving ability and how often driving assessments were used. The survey also looked at their satisfaction with the current procedure of assessing competence to drive in patients with dementia and how they thought this could be improved.

\section{Method}

A questionnaire was sent to 76 old age psychiatrists who are registered to attend the Northern Regional Old Age Psychiatry Meeting which is held four times a year. This included consultants, specialist registrars and non-career grade doctors working in the counties of Tyne and Wear, Durham, Northumberland, Cumbria, Dumfriesshire and Teeside. The questionnaire asked respondents to agree or disagree with a list of statements (Box 1). Space was also available for comments. We included statements taken directly from the forms issued by the DVLA for drivers with cognitive impairment (Neuro 2C), to determine what respondents thought were relevant indicators of driving ability.

The questionnaire was piloted and changes were made to ease completion. It was then sent to the above group and a further copy was sent 2 weeks later to improve response rates. 